\title{
Learning Theories in Association with Improving University Students' Learning Potential
}

\author{
Wilailak Ounjit (Laila) \\ Faculty of Humanities and Social Sciences, Mahasarakham University, Thailand
}

\begin{abstract}
The research, entitled "A Study of Guidelines for Developing University Students' Learning Potential", was a Qualitative Research. The objectives were:

1) to study factors affecting the students' learning potential development at the University, and 2) to enhance the students and instructors' teaching related courses and to participate in searching for the students' learning and potential development in regards to quality educational standards as well as relevance to the students' needs. The instruments for collecting data were the Focus Group Discussion, Semi-Structured Interview, and Behavioral Observation Form. The research findings found that the factors affecting the students' learning potential development were instructors, curriculum, environment, and the students themselves. The guidelines in developing the students' learning potential included the preparation of curriculum to serve the students' needs, the evaluation of readiness and preparedness of those students who wanted to study, the arrangement of the learning process to be appropriate for the students, as well as media, materials, and a place which facilitated knowledge management and development for the students.
\end{abstract}

\section{Introduction}

The educational development plan and quality assurance of the Center of Educational Development and Quality Assurance, specified in Section 4: The Guideline in educational management, Principle 22, based on the principle that "Every student has the ability to learn and develop himself. In addition, the student is the most important person. So, the educational management process had to develop the students' full potential". According to the educational quality plan of students as mentioned heretofore, the focus on the educational quality development of University Students, without specification in any field of study, includes the students majoring in
Community Development. Therefore, the assessment of students in every major would be evaluated from their grade point average in each semester. As a result, it could be seen that the educational quality of students majoring in Community Development needed to be closely monitored in order to gain a useful, appropriate, and suitable recommendation for the learning potential development of these students.

\section{Research Rationale}

The Community Development major has been offered at the University since 1989 . Hundreds of knowledgeable, competent, and high quality scholars have graduated from the University's Community Development program and they continue to work successfully in many fields. They work in many occupations and fields as developers, instructors, and organization officers at national and international levels. According to the university policy providing opportunities for those who were interested in majoring in Community Development, the number of students increased while the number of instructors remained constant. As a result, the instructional quality for students majoring in Community Development did not develop as a specified goal. This was determined by looking at the students' grade point averages, whether in the students' major course, elective courses, or other courses, their reports, class presentations, and finally, their publications. The students majoring in Community Development had low grade point averages and thus were evaluated and measured via the educational quality assessment which considered the results of examination findings and reports, presentations, and class participation. Consequently, those students' quality of education standards did not satisfy the standards based on the educational development plan and quality assurance as specified by the university. 
This research focused on the application of approach in the learning process, an approach which would support the students' learning potential development based on the needs of students and university by focusing on the students' participation to search for guidelines in developing the learning potential. In addition, there was cooperation and input as well as the request for collaboration from various sources who interacted with the students, such as the instructors and various officers who were a part of the students university experience. The most important person was the student. In the learning process, it was necessary to be managed relevant to the students' aptitude, thinking process, skill, virtue, and morality. The instruction might be adjusted by organizing the obvious goal. In addition, the relevant persons who interacted with the students whether they were instructors or officers should be allowed to play more significant roles and participate with the students. Therefore, the researcher would like to study by surveying the guidelines in developing learning potential of students majoring in Community Development of the University with the ultimate goal that the students would be able to learn, develop their thoughts, and efficiently deal with different problems. This, in turn, would lead to guidelines in learning potential development of sustainable learning in order to develop the students' awareness and responsibility, search for knowledge, competency, and the ability to work in harmony with others, whether they were the instructors or students.

\section{Objectives}

1. To study the factors affecting the learning potential development of students at the University.

2. To enhance the students majoring in Community Development, instructors, and related officers to participate in developing University Students' learning potential development in order to be quality based on educational standard as well as relevant to their needs.

3. To enhance and develop the University Students' learning potential development.

\section{Operational Definition}

1. Development referred to the way to make something better or develop (The Royal Institute, 1999). In this case, it referred to the technique in causing the University Students' to improve their learning potential.

2. Learning Potential referred to the University Students' efficient studying regarding the following aspects: skill, morality aspect, and the willingness to volunteer.

3. University Students referred to as first year to fourth year Bachelor's Degree Students studying in the University, including both full and part time students.

\section{Conceptual Framework and related Literature}

The literature supporting the conceptual framework of this study includes:

1) The learning approach, 2) Learning Theories, 3) The approach and direction in educational management in Higher Education. According to related literature studies, the researcher applied it as a conceptual framework of this study as follows:

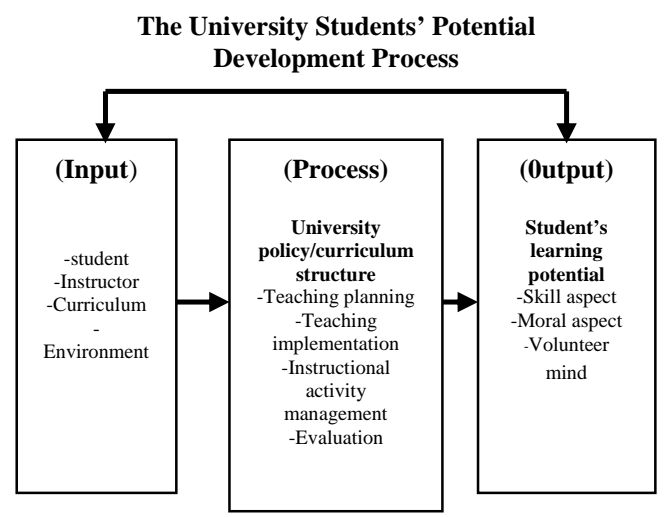

Figure 1. the University Students’ Potential Development Process

This study was a Qualitative Research including boundary of technique for implementing the study as follows:

1. The boundary of population and samples. The samples in implementation of the research were 35 Students majoring in Community Development at the University of Thailand, with learning achievement in the highest level and lowest levels, including five of the first year students, and the second to the fourth year students, ten students each year. There were five part time students and five full time students, five alumni in Community 
Development, six instructors in the Department and two related officers.

2. The instrument using in this research included the Focus Group Discussion, Semi-structured Interview, and Behavioral Observation.

3. The steps of research methodology were as follows:

3.1 Collect data from Semi-structured Interview by separately interviewing six instructors and two related officers.

3.2 Collect data five times from Focus Group Discussion by collecting the first to the fourth year students, once a year, a total of four times, and five alumnus in Community Development.

3.3 Collect data from Behavioral Observation from practice behavior coupled with classroom as well as the study behavior outside the class.

3.4 The steps of the collection of data analysis collected and group into categories.

3.5 The steps of reflection and presentation of research findings for the samples and related people for planning to solve problem as well as developing the students' learning potential.

\section{Literature Reviews}

\section{Learning Theories}

Many Theories were studied and designed as Learning Theories by psychologists. However, there were only three theories which were repeatedly mentioned by the researcher; Behavioral theory, Cognitive theory, and Social Cognitive Learning theory. The theoretical approaches from Surang Kowtrakool's (2002) book were collected by the researcher and are as follows:

\subsection{Behaviorism Learning Theory}

The Behaviorism Psychologists classified human behavior into two types:

1. Respondent Behavior refers to the behaviors occurring by stimulus. When there is stimulus, the observable response would occur.

2. Operant Behavior is the behavior emitted by humans or animals without specific stimulus. This type of behavior affects the environment. The theory explaining the first kind of learning or Respondent Behavior is called the Classical Conditioning Theory. Thus, the theory of knowledge explaining the Operant Behavior is called Operant Conditioning
Theory. The assumptions of the Behaviorism Theory are:

1. Every behavior occurred by knowing which is observable.

2. Each kind of behavior is aggregate to various kinds of learning.

3. Reinforcement could cause the behavior to occur.

\subsection{Constructivism Learning Theory}

Constructivism Theory consisted of major principles that during the process of learning, the learner has to be active as well as assembling knowledge. Constructivists or philosophical view and knowledge of construction as two theories include:

1. Cognitive Constructivism refers to learning theory in Constructivism based on Jean Piaget's (1970) Developmental Theory. According to this theory, the students are active as well as constructing their own knowledge. Social interaction causes cognitive dissonance. Therefore, the students have to adapt former knowledge with new information until there is cognitive dissonance or new knowledge.

2. Social Constructivism is a theory based on Vygotsky's Developmental Theory that in viewing the students construct their own knowledge by social interaction with the others (adult or friend) while they participate in activities within Social Context which is an indispensable variable. Social interaction causes the students to construct knowledge through the transformation of previously obtained knowledge being more correct, complex, or extensive. There were common characteristics in Constructivism as follows:

1. The students or examiners construct their intellect in what they learn by themselves.

2. Learning new things is based on one's prior knowledge as well as new discoveries.

3. Social interaction is important for learning.

4. Management of the environment and activities which are similar to one's reality could help one to have significant information.

The details of Cognitive Constructivism are well known to be educational background material as Bruner's Learning by Discovery, which is cited by the researcher as follows:

Jerome S. Bruner [2] believed that the knowledge would occur when students interact with the environment, which leads to the discovery of 
problem solving. He called it the Discovery Approach. Some educators preferred to call it "Inquiry learning" and noted the discovery approach and inquiry learning separately. In the Discovery approach, the teachers coordinate the environment as well as provide different kinds of information regarding what they need their students to learn, the objective of the lesson included questions for example, expecting their students to search for and discover the answers by themselves. In inquiry learning, the objective is training the students to be able to point out what the problem is from the existing information, and search for techniques to solve problems by using the existing information.

\section{Theoretical background}

Bruner [2] believed that the understandable knowledge would occur when the students collected information from environmental interaction and surveying. He also believed that an individual's perception is a result caused by selection or attention to those things since the students are enthusiastic, knowledge would be obtained by discovery, which is the driving force for environmental surveying behavior as well as learning by discovery. The basic approach of the Discovery Learning Theory included:

1. Learning is a process where the students are interacting with the environment by themselves. There were changes as a consequence of interaction, which do not only occur in the students but also in the environment.

2. Each student has different types of experience and background knowledge. Knowledge will occur by the relationship between new discoveries and new experiences and understanding, constructed by the student.

3. Intellectual Development could be clearly observed by the students and they were being able to receive various alternative stimuli simultaneously.

Besides, Bruner provided the instructional principles as follows:

1. There were differences between a child and an adult's thinking. When children do something wrong, the adults should consider the children's intellectual development at different age levels; therefore, children will have different thought process from adults. As a result, teachers and those with the responsibility of education should understand the level of thinking obtained by children at each age, and also keep that in mind that their cognitive process is different from adults, known as Intellectual Empathy.

2. The students' importance should be emphasized by assuming that the students are able to manipulate their own learning activities, which is called Self-Regulation. They would initiate and do something independently. Therefore, the teachers or those with the responsibility of teaching or providing training need to manage the environment and simplify the learning by providing the opportunity for students to interact with environment.

3. In teaching, one should begin from the experiences which the students are familiar with, or real life experiences to the future experiences, so that the students can understand more easily. For instance, teaching students how to use a map should begin with the province where they live in before studying other provinces or the national map.

Moreover, Bruner also viewed that during instructional management, the teachers should be able to provide experiences in order to help the students to be ready without waiting for them to be ready naturally, which is time consuming. According to Bruner's approach, readiness could be stimulated to occur more rapidly.

In addition, he also recommended that for instructional management, Developmental theory should be considered as a connector between Theory of Learning, and Theory of Instruction, which meant that the Developmental Theory would determine the content or knowledge as well as a teaching strategy. In order to select the content or knowledge to teach students, one must consider the developmental level as well as the competency level of the students. We adapt the content to be relevant to the child's capabilities in learning or perceiving through appropriate techniques with their age. Therefore, we should teach children with existing readiness without delay. As stated by Bruner, "Any subject can be taught effectively in some intellectually honest form to any child at any stage of development." In readiness, it refers to the children's ability to learn simple skills first as a foundation for the next difficult skill. Bruner stated that "One teaches readiness or provides opportunities for its nurture; one does not simply wait for it.” Readiness, in these terms, consists of mastery of those simple skills that permits one to reach higher skills. He viewed that in educational management, the subject content should be continuous. If we know which subject is necessary for children or when it should be used, that content subject should be emergently taught to 
students whilst they are young, by adjusting the subject content to be appropriate with their competency or perception. Consequently, if the adequate technique is employed, then we should be able to teach any subject at any age level. According to this perspective, the instructional management should be a "spiral curriculum" by organizing the subjects to be continuously connected as well as intensively, complexly, and broadly based on students' experiences. The same content would be studied from Elementary Education to the University Level whether it is Mathematics or Physics, they should study all of them.

\subsection{Social Cognitive Learning Theory}

Social Cognitive Learning Theory is a theory developed by Bandura [1] at Stanford University, the United States of America. He believed that most learning is caused by "observational learning" or "imitation." Furthermore, human beings always interact with their surrounding environment. $\mathrm{He}$ explained that learning occurs by interaction between students and their social environment. Both student and environment influence each other. Later on, the theory was changed to be known as Social Cognitive Learning Theory, since he found from his experiment that one major cause of observational learning was that students had to correctly encoded the information observed into the long-term memories. Moreover, they had to be able to evaluate whether or not their imitation were good and verify them. They needed to control themselves through meta-cognitive structure. $\mathrm{He}$ concluded that observational learning is a Cognitive Process. The Social Cognitive Learning Theory consisted of general principles of teaching by using the Social Cognitive Learning Theory to:

1. Specify the objective for students to act, behave, or write the behavioral objective.

2. Give an example of many actions which might be a real life person, cartoon, film, video tape, television, and different types of media.

3. Provide explanations in alignment with each example.

4. Suggest the observational learning step for students such as asking them to be interested in the knowledge presented to them stimulus needed to pay attention to, or select.

5. Provide time for students with the opportunity to express their behavior as the model, in order to see whether the students could imitate it or not. If they could not perform correctly, the teaching technique might be improved, or the students might be improved.

6. Provide reinforcement for students who can imitate correctly, so that they can have motivation to learn and be a model for the other students.

For all of the three learning theories; Behavioral Theories, Cognitive theories, and Social Cognitive Learning, are classified as the learning approach based on its theoretical framework. In learning management, those who manage the learning or teachers, need to know and understand the approach of that theory in order to make the necessary adjustments for learning in the future.

\section{Analysis of Findings}

Part 1: The overall expectations of
lecturers and students majoring in
Community Development, for the overall
expectation of lecturers and students majoring in
Community Development, it could be concluded as
follows

1. The lecturer's expectations on working as a department lecturer: most of them expected to play their role and function as the department lecturer by focusing on "Student-Centered," considering the students' benefits as a major thing, trying to integrate the uniqueness between students and lecturers as well as the faith in honest occupation. The department lecturers had similar ideas in that being university lecturers required them to be role models as well as supporters for their students. Although some of the lecturers never anticipated being lecturers because it was the first job that they held. However, they thought that they would try their very best.

2. The lecturer's expectation for students: most of the lecturers in the department wanted their students to learn how to develop themselves more, to apply theory from the class into their daily lives as well as solve their problems by themselves. Also, every lecturer was expected to have the awareness in doing the developmental work for their community and society, as well as participating in performing the activities of the department.

3. The students' expectations in studying Community Development: most of students expected to meet new friends with similar interests in issues. Moreover, some of them also expected to 
study by themselves more, in order to have potential in applying the obtained knowledge in developing people, their community, and themselves. In addition, a major objective expected by the students majoring in Community Development included graduating according to schedule so that they could use their degree when applying for their preference and secure post such as bureaucratic work, development work, or other kinds of work. Furthermore, some of them also expected that when they enrolled in this field of study, it could lead to playing a role in establishing the important plans or policies of government. Since they believed that their study in this field would help them in expressing their opinions freely as well as applying knowledge in daily life, they viewed this major field as a bridge to learn more about humans beings' problems and utmost needs. It would aid them in becoming better leaders, possess the courage to think and express themselves, and to have competency in working with efficiency as well as learning about the Esan People/language.

4. The students' expectations of their lecturers: although most of the lecturers had the competency and skill to transfer the knowledge to their students, most of the students still felt the crucial factor was the excessive number of students who came from different families, societies, and localities. Therefore, each of them had their own identity, personality, and habits. The students' view was that if the lecturer had the understanding about each student's individual nature, without focusing on a single standard of lecturing in judging the state of students' self, independence, and expression, then the outcome may have been different. In addition, when the lecturer could apply their real experience aligned with teaching, the atmosphere wouldn't be too serious. Moreover, as a result of the relaxed atmosphere, the students would be more enthusiastic about learning.

Part 2: $\begin{gathered}\text { Factors affecting learning } \\ \text { development of particular }\end{gathered}$
potential
University Students was found as follows
curriculum structure did not have a specific development strategy. As a result, there were students from various fields of study without desirable characteristics and this illustrated the present state of the Community Development Field of Study. It was thus necessary to immediately improve it. In recent times, there were many courses in curriculum of Community Development as well as in other fields of study, such as the Administration and Community Management, which was similar to Community Work Management Course of Political and Governmental College. Therefore, the curriculum structure of Community Development had to develop its uniqueness in order to remain as a viable major offered at the university and to continue to attract students wishing to study in this field. Furthermore, some students were studying in this field but they did not have any real interest in the major.

The instructors and their instructional process aspect found that students were not completing and turning in their assigned reports. Consequently, the students did not get feedback from their report as well as the follow up and evaluation or supervision that normally followed the completion of such reports. Furthermore, most of the instructors had overloaded teaching schedules so some of them were unable to give the necessary time to their students. Per the instructional process, the students had little participation in owing to the focus on lecturing which did not lead to a sharing climate. The students lacked studying skills in speaking, thinking, and expressing themselves.

The students found that some students lacked commitment, copying homework and not adding sufficient analysis to their reports. In addition, some of them did not respect the basic classroom rules. For instance, they were not punctual, were frequently absent, talked in class, and did the other work while they were studying, did not prepare for exams, tended to sit in groups at the rear of the classroom. Moreover, some students showed their inappropriate behavior both inside and outside their classes such as wearing inappropriate clothing, not following the university rules, not offering to volunteer, and just lacked general responsibility. Some of them also had personal problems which adversely affected their grades.

The other environmental conditions found that there were many disadvantages facing the students in regards to available media, microphones, and computers. The media was outdated and needed proper maintenance and improvements. As a result, the students had to use inefficient or unusable materials such as a broken microphone and monitor in the classroom. The students also had to study in classrooms that were too large and this created an atmosphere which was not conducive to participatory learning. Furthermore, there were very 
few of books available for supplementary reading. Consequently, it was yet another obstacle for them during their pursuit of knowledge and learning.

Part 3: The guidelines for developing the learning potential development of students majoring in Community Development with quality based on educational standard as well as relevance to the students' needs.

The students: The student development should begin with the development in virtues, morality, as well as discipline in responsibility and enthusiasm for students, enhancement for students to participate in the activities both of inside and outside classroom, and development of faith, esteem, and ideal in Community Development. Since there were a large number of students, the major cooperators should be appointed for being able to be responsible for cooperating between the instructors and students, and students-students by electing "the head of classroom," who would set the example of the aforementioned attributes. Also, at least once per month, the advisors and students would meet to discuss progress, problems, solutions, etc. It would help in creating a good relationship between the instructors and students. In addition, the relationship among each cohort would improve and develop as well.

The learning process: The instructional adjustment by focusing on participatory process was an important technique needed to be used not only in the classroom but also the field study which was required to encourage the students in sharing, exchanging ideas, or giving constructive criticism. They needed to be encouraged in analyzing the approach, rationales, and theories which would help the students in applying with real situation when they had field work experience. Moreover, the necessary skills for studying and analyzing the community, society, instrument usage training, and skill in keeping and presenting should be emphasized more and that, in turn, could help develop the students' learning potential. For example, techniques in using different picture and charts, as well as adjusting viewpoints and attitudes in activity participation or the development of students' attitude toward studying in general.

The instructor: Every instructor had to take responsibility as the advisor for their students, have a good personality and be able to set a good example for the students. They should have an evaluation principle as well as a neutral attitude, for all of the university students, not just the students in their classes. Besides, the changing of teaching styles by focusing on the students' participation, by giving advance notice of the subjects to be taught next period etc., which would help the students to properly prepare for class assignments. For reports, the instructor should give advice or an opinion on the report or assigned work and return the work to the students and allow plenty of time for the students to improve and amend the work in order to do the task more efficiently in the future.

The other environmental conditions: The media, technology, and materials in classroom should be systematically and sufficiently arranged for students. Furthermore, the supplementary modern books should be organized. The E-book system and facilities as well as parking lot and food stores, should be organized. All of these would affect the students' learning potential.

\section{Discussions}

Part 1: Factors affecting the learning potential development of Students with majoring Community Development

The students found that some students could assert themselves more in order to improve their learning skills and assignment grades, etc. For instance, public speaking, process management with community, mind map writing, SWOT analysis technique, and not being able to speak in front of the class, no preparation before the exam by reading in front of the exam room, and a general lack of enthusiasm for studying. For activity participation, the students still had inappropriate behavior both inside and outside their classroom, lacked the eagerness in learning, and also lacked the willingness to actively participate in learning. They lacked awareness in development work and did not appear to be mindful of volunteering as part of their civic duty. Some of them had personal problems affecting their studying which caused them to lack concentration while studying and this ultimately affected their graduation status. It was supported by Kumaree Chaiyakul [3] stating in the nature of learning that the students want, motivate the students to learn, and the interesting stimulus before learning, the stimulus should be interesting and touchable for students so that they would be enthusiastic to study. 
The curriculum and instructional management found that there was no unique characteristic or science for development work of Community Development Curriculum. As a result, there were various styles of students and no characteristic relevant to the objective. Therefore, recommendations for improving the new curriculum in 2010, the courses with uniqueness of community development work different from other fields, should be added. For example, Community Development Theories, or the English Course, should be adjusted as a compulsory course. Moreover, for the improvement of content there should be more focus on the work force needed to accomplish these objectives. As for the instructional process, the students should be encouraged to construct their learning with their friends and instructors as well as studying by themselves. The relevant content or courses that should be added include learning to work with community, city, private organization, communication company for community development (technique of community development), the field work with content relevant to current situation, focusing more on IT, basic knowledge of Geography Program, and the courses relating to agriculture which could be useful to the villagers. It was supported with the learning style of students in future university concluded by San Worain [10] based on framework of the 15 year long range Higher Education Plan (2008-2022) that the students' learning style in future university, the extracurricular should be supported, the youth and students' learning as life skills, and social skills. Based-line competencies should also be added. The academic knowledge and competency as the learning camp, volunteer camp, or project and extra curricular activity should be collected. In addition, the extra curricular should be integrated with real life in curriculum by focusing on instruction in development activity for increasing different skills which supporting the national development, competency level of the country, and competition in various aspects.

The instructors found that some instructors did not have enough time to evaluate or supervise as specified by the university since they had too overloaded teaching schedules and thus did not have time to properly attend to their students. They had to advise their advisees. They should be unified, fair, and open minded in listening to the students' opinions. All of these factors affected the students' learning. Besides, their ideas or suggestions for students as well as the climate in sharing between the instructors and students would help the students to be active in developing their own learning potential. It was supported by the approach of Kumaree Chiayakun that after the students had the need to study there were interesting stimuli from the beginning, and this would affect their response by different techniques until they were able to interpret as perception, remembering, integrating knowledge, comparing, an reasonable thinking until they were satisfied and had applied them for quality of life development. They could be professional as well as honored by society as prestigious social dignitaries. On the contrary, if there is not sufficient process for readiness preparation, the opposite outcome would occur. Whereas Waree Tirajit (cited in Apon Jaitieng) stated the objective of knowledge management relevant to the above approaches that: it was the enhancement for students to be assertive and participate in studying as well as serve the objective of curriculum so that the students would be able to think, act, and solve problems [4]. As a result, they had process skills to be competent, good, happy, and have a state of being Thai.

The university structure/system/policy found that the problem of the university structure or policy that offering a large number of students to enroll in the program, would cause the lack of principle development in selecting the students with real public mind and the need for studying. Consequently, there was instructional management for large group of students.

Part 2: The guidelines in developing the learning potential of students majoring Community Development with quality as educational standard and relevance with students' need

The students, the students' development and adjustment in virtue and morality should be emphasized. In addition, the discipline in responsibility and enthusiasm should be developed so that the students could participate in activities both inside and outside their classroom. The students should develop their faith, esteem, and ideal in Community Development. The plan should be performed through the curriculum as well as amongst colleagues in the university. The third and fourth year students had to create learning for the first and second year students. For the instructional process, the instructional process should be modified 
emphasizing on process and the usage of instrument for internship. The real practice should be more focused. The instructional model of sharing or criticizing in class in regards to the issues regarding to learning as well as the learning of approach, and theory should be trained for analyzing in accordance with context or real situation. The necessary skill in education, (i.e. the skill or technique in presenting information in order to be interesting), such as picture use technique in using different pictures or charts, should be developed. In addition, the students' approach and attitude toward participating in the activity should be modified so that they can generate creative ideas. The image of activity students should be created as "The activity had to be aligned with learning." The Laboratory for Community Development was another guideline for enhancing the students' operation, such as the library of this field, including the supplementary books or the rooms for students' sharing or meeting. For the specific area of Community Development, it would help every cohort student to participate in the common activity and make relationships between themselves to support each other, especially in studying. Regarding the field of study in teaching, the content material should be improved for each semester in order to be balanced and congruent. In addition, the English Technical Term should be included in each course so that the students would have the opportunity to universally learn the development task. For the instructor aspect, the instructors had to take responsibility in being advisors for their students. In addition, they should have unity and adjust their personality to be ready to listen to every student's opinion, and be fair with them. Furthermore, they should give advice in the assigned task and adapt their teaching techniques in order to foster a sharing climate. For the guidelines for developing the students' learning potential to include quality as an educational standard, and the relevance to their needs, the indispensable and urgent model and guidelines were: the readiness assessment of students who would enroll in this field in order to have adequate instructional management for them. The instruction during each semester was planned for balance so that the students would have more time for participating in other activities besides instruction. The students' specific skills should be developed and enhanced. Moreover, media, equipment, and places for facilitating learning and development, as well as the provision of new books relevant to every course of study, should be provided. The library of department should be organized so that the students could access it for research and general reading. The block or lecturer's community channel for their students to send information or work more conveniently and easily. Furthermore, the lecturers should have criteria for scoring the same standards as well details to score their coursework, in advance of assigning tasks to the students. Moreover, competent and direct experienced speakers should be invited in order to provide additional knowledge and learning opportunities for the students.

According to the model or guidelines in developing the learning potential of students majoring in Community Development, it was supported by the approach in educational management as Research-Based Learning as Krisda Krudtong's statement [5] that the studying changed from "Learning by listening/answering the right answer" to be "Asking/finding answer by oneself." The goal was changed from "Learning by memorizing/ practicing/ using," into "Thinking/searching/ finding." The teaching technique was changed from "Learning by lecture," into "Counseling." The instructor's role was changed from "Being the practitioner," into "Managing the students to practice."

\section{Conclusions}

The research in learning potential development of students indifferent fields of study, might be conducted which should be supported so that the findings of problem analysis from each field would be collected as well as adapted to the teaching process. In addition, the study curriculum should be constructed to be congruent with the students' needs and university policy which would lead to efficient instructional management according to the educational development and quality assurance plan of the university.

\section{References}

[1] Bandura, A., (1986), Social Foundation of Thought and Action: a Social Cognitive Theory. Englewood Cliffs, N.J.: Prentice-Hall.

[2] Bruner, J., (1960), The Process of Education. Cambridge, MA: Harvard University Press (Reprinted 1977) 
[3] Chaiyakul, K., (2009), The Learning Approach. Hyperlink "http://school.obec.go.th/sup_br3/m_05.htm" http://school.obec.go.th/sup_br3/m_05.htm (Access date: $20^{\text {th }}$ December 2009).

[4] Jaitieng, Apon, (2009), Teaching Principle. The $2^{\text {nd }}$ Printing. Bangkok: Odian Store.

[5] Krudtong, K., (2009), The Educational Management in Research-Based Learning. Hyperlink http://www.ssru.ac.th/linkssru/Department/Research/cel. htm" http://www.ssru.ac.th/linkssru/Department/Research/ cel.htm (Access date: 19 ${ }^{\text {th }}$ December 2009.

[6] Kowtrakool, S. (2002) Pshychology for Education. Pimlak: reprint 5: Chulalongkorn University.

[7] One particular University. A Report of Quality Assurance in 2009. (2009), University, 2009.

[8] Paiget, J., (1970). The Science of Education amd the Psychology of the Child. NY: Grossman.

[9] The Royal Institute, (2008) Dictionary: The Royal Institute Issue. Bangkok: Odien Store.

[10] Wora-in, S., (2009) The Conclusions of Policy Framework of Long Range Higher Education Plan. (20082022) "http:// pirun.ku.ac.th/ psdvcw/student01.pp" http:// pirun.ku.ac.th/ psdvcw/student01.pp (Access date: 19 December 2009). 